\title{
Performance Measurement and Benchmarking of Large-Scale Tourist Hotels
}

\author{
Tien-Chin Wang, Huang Shu-Li* \\ Email address: \\ tcwant $a$ kuas.edu.tw (Tien-Chin Wang), carolhuag@yahoo.com.tw (Huang Shu-Li) \\ ${ }^{*}$ Corresponding author
}

Department of International Business, National Kaohsiung University of Science and Technology, Kaohsiung, Taiwan

To cite this article:

Tien-Chin Wang, Huang Shu-Li. Performance Measurement and Benchmarking of Large-Scale Tourist Hotels. International Journal of Business and Economics Research. Vol. 7, No. 4, 2018, pp. 97-101. doi: 10.11648/j.jiber.20180704.13

Received: June 11, 2018; Accepted: August 3, 2018; Published: August 13, 2018

\begin{abstract}
Taiwanese tourism policy underwent a major change in 2008 when restrictions were gradually relaxed on Chinese tourists visiting Taiwan. According to the Tourism Bureau of Taiwan's statistics, the overall number of mainland tourists increased from 329,204 in 2008 to 4,184,102 in 2015; however, there was a $16.1 \%$ reduction $(670,000)$ occurring in 2016 . This significant event will cause more harm than good to Taiwan's all-important tourism industry. In response to such contractions, this study applied cluster analysis combined with entropy to derive suitable clusters useful towards identifying the best market performers among hoteliers through a measurement of large-scale tourist hotels' operational performance. This may signal a benchmark for the improvement of poor performance hotels. Entropy is used as an objective weight method to calculate the relative importance of all salient attributes by comparing the entropy values of each given attribute. Large-scale international tourist hotels have become the market mainstream in Taiwan; therefore, 17 tourist hotels with more than 5000 employees yearly were selected to become part of this study. Operational performance was measured by attributive means of occupancy rate, average room rate, average production-value-per-employee, total number of domestic tourists, and total number of foreign tourists (including overseas Chinese). A significant $\mathrm{F}$ value of the ANOVA analysis indicates that there is at least one significant difference found between the two clusters. Further post-hoc analysis uses the Scheffé method to identify any difference found between clusters and to determine the best performance cluster useful as a benchmark. The methods of this study are different from those of previous studies because of the use of a Data Envelopment Analysis (DEA) technique or mix, while there is also applied cluster analysis combined with entropy. Clear indicators are deemed useful for exacting improvement standards among under-performing tourist hotel properties.
\end{abstract}

Keywords: Performance Measurement, Cluster Analysis, Entropy, Tourist Hotels

\section{Introduction}

In 2008, Taiwan's tourism policy underwent a major change when restrictions were gradually relaxed on Chinese tourists visiting Taiwan. According to the statistics from the Tourism Bureau of Taiwan, the overall number of Chinese tourists increased from 329,204 in 2008 to 4,184,102 in 2015, however, there was a significant reduction of 670,000 , a decrease of $16.1 \%$, in 2016 . It is possible that the decrease in the number of Chinese tourists may turn from a temporary phenomenon to a regular one. This will in effect cause more harm than benefit to the Taiwan tourism industry [1].

The most concerning thing for hotel management is any performance difference with other firms and of course what factors influence them [2]. Lin and Chen pointed out that hotel accommodation is a labor-intensive industry where there is a considerable investment of manpower to provide high quality service for consumers. Cheng et al. concluded that large-scale international tourist hotels have become the market mainstream in Taiwan. The purpose of this study is to use hierarchical cluster analysis combined with entropy to derive the clusters and to identify the best market performers through a measurement of the tourist hotels operational performance which serves as a benchmark for the least ones to make improvement [3-6].

The methods of this study are different from those of previous studies $[7,4,8,9]$ because of the use of a Data 
Envelopment Analysis (DEA) technique or mix, while there is also applied cluster analysis combined with entropy. In this study, 17 tourist hotels with more than 5000 employees employed year-round in Taiwan were selected. Operational performance was measured by attributive means of occupancy rate, average room rate, average production-value-per-employee, total number of domestic tourists, and total number of foreign tourists (including overseas Chinese) according to The 2016 Yearly Operation Report on Tourist Hotels as published by the Tourism Bureau of Taiwan. The following sections present the literature review, followed by a data description and methodology, results, and a conclusion.

\section{Literature Review}

Poldrugovac et al. considered perishability as one of the salient characteristics of hotels; therefore, hotel managers generally use classic performance tools to measure the extent of their success, such as revenue-per-available-room, occupancy rate, return-on-investment, and other similar indicators. According to Singh and Schmidgall, the results of questionnaires from 81 U.S. hotel financial managers' subjective cognitive assessment is that the average room rate ranks as the most important indicator of all. The hotel industry are labor-intensive and task-oriented industries for the reason of depending on personnel delivery services [12, 13]. Therefore, the service sector needs to evaluate performance more than other areas, such as with average occupancy rate, operating revenues, average production-value-per-employee $[14,15]$. In addition, two ways that Taiwan's hoteliers have chosen to respond to competition is to continually target international tourists and domestic tourists in order to increase the sources of customers [16]. This study selected occupancy rate, average room rate, average production-value-per-employee, total number of domestic guests, and number of foreign guests (including overseas Chinese) as performance indicators. [10, 11].

Benchmarking is a systematic process of comparative measurement for the exact purpose of attaining continuous improvement [17]. Most studies have applied the DEA technique, whether using the original or derivative models, to measure hotels' operational performance and to identify benchmarks. Chiang et al. found that not all of the franchised or internationally-managed tourist hotels are more efficient than independently-owned ones. Yang and Lu discovered the international-chain tourist hotels were more competitive and could easily serve as benchmarks. Chen also concluded that chain hotels are generally more efficient than independently-operated hotels. Wu and Song considered it as difficult for an inefficient Decision Making Unit (DMU) to be regarded as a conventional reference set as its reference targets become better efficient. This is especially true because the reference set may not be inherently similar in its given practices. They used DEA and cross-efficiency evaluation methodology to evaluate the operational efficiency of 21 international tourist hotels in Taipei over a five year period
(2003-2007), then applied hierarchical cluster analysis to divide this grouping into $11 \mathrm{sub}$-groups to find performance benchmark hotels within individual groups. The best performers in every one of the clusters will be the primary benchmark used by the other hotels within the cluster. Wu et al. used the dynamic DEA method to explore the performance of international tourist hotels in Taiwan for the period of 2006-2010, and they proposed a benchmarking framework useful for assessing hotel efficiency and effectiveness. The results clearly showed that 9 out of the 80 international tourist hotels observed were recognized as outstanding performers. The business strategies of these hotels are respectively: employees (intensive versus economical labor forces), products (room versus F\&B services), prices (extremely expensive versus very inexpensive room rates), guests (business versus tourism guests), among others (e.g. location advantages) [7-9, 18, 19].

\section{Data Description and Method}

\subsection{Hotel Sample}

The data were obtained from The 2016 Yearly Report on Tourist Hotel Operations published by the Tourism Bureau of Taiwan. According to the report, there were 17 tourist hotels with more than 5,000 employees employed annually in Taiwan. The five criteria are as follows: Occupancy rate, average room rate, average production-value-per-employee, total numbers of domestic tourists, and total number of foreign tourists (including overseas Chinese) used for the measurement of overall performance. The three criteria, including occupancy rate, average room rate, average production-value-per-employee, are described, as follows:

1. The occupancy rate: The actual number of rooms sold, divided by the total number of rooms available for sale.

2. Average room rate: Room operating income, divided by the actual number of rooms sold.

3. Average production-value-per-employee: Total revenue, divided by total number of employees.

\subsection{Method}

This study proposes the combination of entropy weights and cluster analysis used to assess operational performance. The main purpose of cluster analysis is to group relatively homogeneous cases within themselves and heterogeneous between each other, which can be divided into a hierarchical cluster analysis and non-hierarchical cluster analysis structure. This study used the Ward's method based on squared Euclidean distance, and agglomerative algorithm in driving the clusters. Afterwards, it is necessary to draw a tree diagram to determine the best cluster arrangement. [20, 21]. The entropy weight method (EWM) was first used by Shannon to measure the uncertainty of the message. It is an objective weight method that can calculate the relative importance of all attributes by comparing the entropy values of each given attribute [22].

A procedure of the entropy weight combining cluster 
analysis is used to first let a total number of $\mathrm{m}$ samples be evaluated by using $n$ criterion. In order to provide an objective basis for comparison among the assessment criteria, the collected data are normalized. The calculation for normalization can be formulated as formula (1)

$$
\begin{gathered}
r_{i j}=\frac{x_{i j}}{\sqrt{\sum_{i=1}^{m} x_{i j}}} \\
i=1,2, \ldots, m, j=1,2, \ldots, n
\end{gathered}
$$

Where $r_{i j}$ is the value after normalization, $x_{i j}$ is the value before normalization.

Then calculate the entropy value of each criterion, then evaluate objective weights with entropy and weight the normalized values. The formula is as the following:

$$
\begin{aligned}
& e_{j}=-\frac{1}{\ln m} \sum_{i=1}^{m} \ln r_{i j} \\
& i=1,2, \ldots, m, j=1,2, \ldots, n
\end{aligned}
$$

Where $e_{j}$ is the entropy values of the $j t h$ criterion. $\ln m$ is a constant to make sure the value of $e_{j}$ is between 0 and 1 .

The formula for calculating the weights of criteria is as follows:

$$
\begin{aligned}
& W=\left(w_{1}, w_{2}, \ldots, w_{n}\right) \\
& \mathrm{w}_{j}=\frac{1-\mathrm{e}_{j}}{\sum_{j=1}^{\mathrm{n}} 1-\mathrm{e}_{j}}
\end{aligned}
$$

$$
i=1,2, \ldots, m, j=1,2, \ldots, n
$$

This study used One-Way Analysis of Variance (One-Way ANOVA) to test whether there is a significant difference in the clusters' established mean. A significant $F$ value of the ANOVA analysis indicates that there is at least one significant difference found between the two clusters, and further post-hoc analysis uses the Scheffé method to identify the difference between those clusters and to find the best performance cluster useful as a benchmark.

\section{Results}

The hotels with more than 5,000 employees are divided into 3 clusters (see Figure 1). Table 1 shows the results of One-Way ANOVA and post hoc. The three clusters have significant differences in the average room rate, average production-value-per-employee, and the number of foreign guests (including overseas Chinese). The occupancy rate and the total number of domestic tourists are not significantly different. The average room rate of cluster 2 is significantly different from that of cluster 1 and 3 . The mean of cluster 2 is greater than that of cluster 1 and 3, which is used as the benchmark for cluster 1 and 3 . The average production-value-per-employee of cluster 1 is significantly different from that of cluster 2 and 3 . The mean of cluster 2 and 3 is greater than that of cluster 1 , and they are the benchmarks for cluster 1 . The number of foreign tourists (including overseas Chinese) in cluster 3 is significantly different from cluster 1 and 2 . The mean of cluster 3 is greater than cluster 1 and 2, and it is the benchmark.

Table 1. Results of One-Way ANOVA and Post Hoc.

\begin{tabular}{llll}
\hline Criteria & $\begin{array}{l}\text { Mean of Clusters } \\
\text { in each criterion }\end{array}$ & ANOVA Results & Post Hoc Results \\
\hline & $\mathrm{C} 1=0.0617$ & & \\
Occupancy Rate & $\mathrm{C} 2=0.0632$ & $F=0.057<F_{\text {crit }}(2,14,0.05)=3.74 ; \mathrm{Sig}=0.945$ \\
& $\mathrm{C} 3=0.0637$ & & \\
& $\mathrm{C} 1=0.0364$ & & \\
Average Room Rate & $\mathrm{C} 2=0.0766$ & $F=14.903>F_{\text {crit }}(2,14,0.05)=3.74 ; \mathrm{Sig}=0.000^{* * *} \quad \mathrm{C} 2>\mathrm{C} 1, \mathrm{C} 3$ \\
& $\mathrm{C} 3=0.0529$ & & \\
& $\mathrm{C} 1=0.0396$ & & \\
Average Production- Value-Per-Employee & $\mathrm{C} 2=0.0686$ & & \\
& $\mathrm{C} 3=0.0658$ & & \\
& $\mathrm{C} 1=0.0139$ & & \\
Total No. of Domestic tourists & $\mathrm{C} 2=0.0020$ & & \\
& $\mathrm{C} 3=0.0047$ & $\mathrm{C} 1$ \\
Number of Foreign tourists (includes Chinese & $\mathrm{C} 1=0.0275$ & & \\
Overseas) & $\mathrm{C} 2=0.0349$ & $F=15.973>F_{\text {crit }}(2,14,0.05)=3.74 ; \mathrm{Sig}=0.000^{* * *} \quad \mathrm{C} 3>\mathrm{C} 1, \mathrm{C} 2$ \\
\hline
\end{tabular}

Note: Cluster $1=\mathrm{C} 1$. Cluster $2=\mathrm{C} 2$, Cluster $3=\mathrm{C} 3$

*** denotes statistically significant at the $1 \%$ level. 


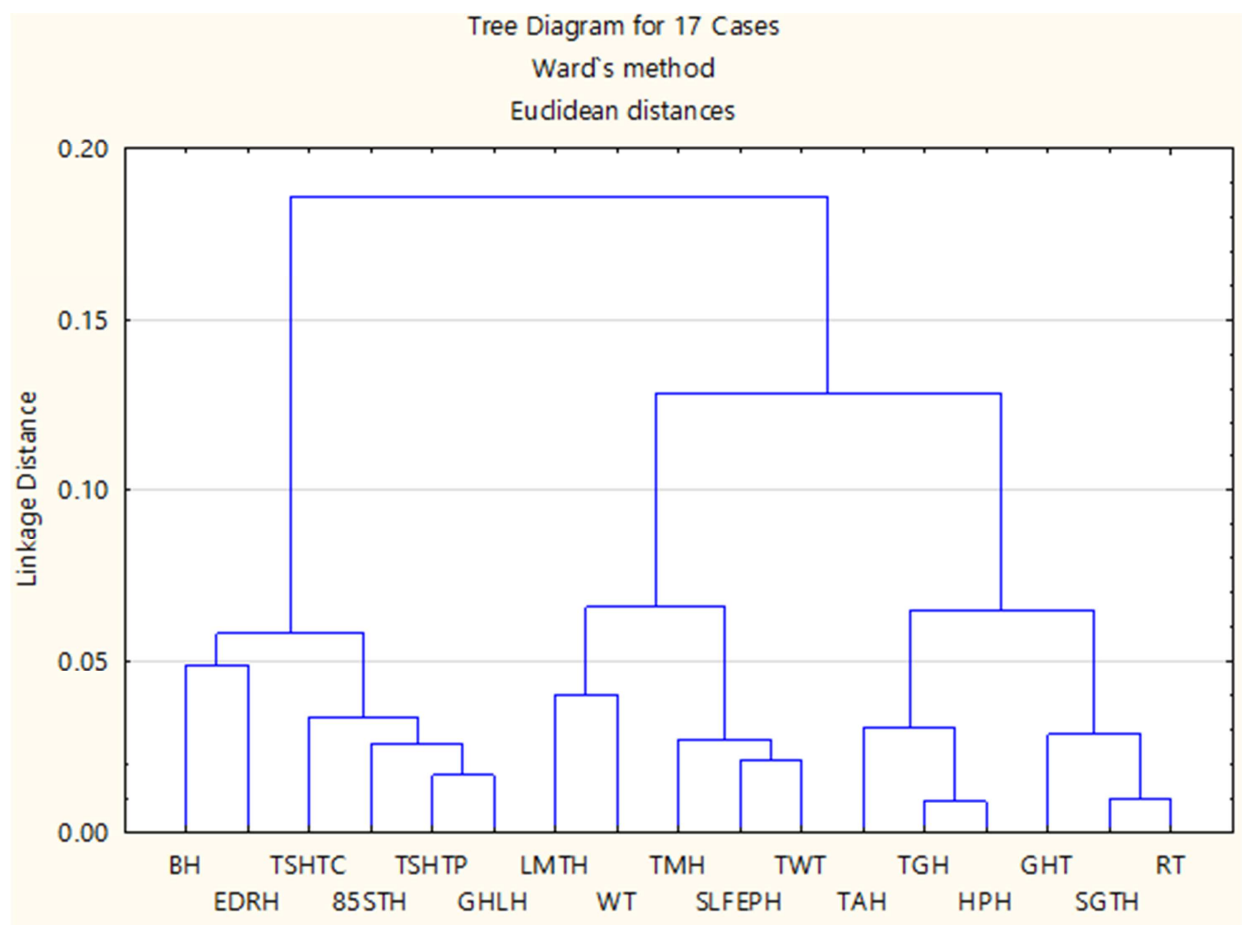

Figure 1. Tree Diagram.

\section{Conclusion}

Due to the scarcity of research on performance benchmarking which employs the general technique of cluster analysis, this study used hierarchical cluster analysis with combined entropy to identify the performance benchmarks of those inefficient hotels in the study as a basis for improvement review. The results of this study showed that the average room rate and the average production-value-per-employee for cluster 2 of hotels are useful as the benchmarks for cluster 1 . The average room rate and the number of foreign guests (including overseas Chinese) for cluster 3 of hotels are also useable as the benchmarks for cluster 1 . This study selected the hotels where the number of employees are more than 5,000 in 2016 to be used as a sample for comparing performance on a similar scale. It also provided a clear indicator of those inefficient hotels deemed useful for exacting improvement standards.

\section{References}

[1] Y. H. Lai, "The Impacts of Contraction in the Cross-Strait Relations on Tourism Industry in Taiwan." Unpublished Doctoral Dissertation, Chinese Culture University, 2017.

[2] E. Claver-Cortés, J. F. Molina-Azorín, J. Pereira-Moliner, "The impact of strategic behaviours on hotel performance," International Journal of Contemporary Hospitality Management, 19 (1), 2007, pp.6-20.

[3] Y. L. Lin, S. Y. Chen, "Data Mining of Operation Performance of Tourist Hotels in Taiwan Journal of Tourism and Leisure Management 2, 2014, pp.20-29.
[4] H. Cheng, Y. C. Lu, J. T. Chung, "Performance benchmarking by improved slack-based context dependent DEA for the hotel industry in Taiwan," Management Review, 28, 2009, pp.141-146.

[5] J. Wu, H. Tsai, Z. Zhou, "Improving efficiency in international tourist hotels in Taipei using a non-radial DEA model," International Journal of Contemporary Hospitality Management, 23 (1), 2011, pp.66-83.

[6] C. Bernini and A. Guizzardi, "Improving performance measurement and benchmarking in the accommodation sector," International Journal of Contemporary Hospitality Management, 27 (5), 2015, pp. 980-1002.

[7] W. E. Chiang, M. H. Tsai, L. S. M. Wang, "A DEA evaluation of Taipei hotels," Annals of Tourism Research 31 (3), 2004, pp.712-715.

[8] J. Wu, H. Song, "Operational performance and benchmarking: A case study of international tourist hotels in Taipei," African Journal of Business Management, 5 (22), 2011, 9455.

[9] W. W. Wu, L. W. Lan, Y. T. Lee, "Benchmarking hotel industry in a multi-period context with DEA approaches: A case study," Benchmarking: An International Journal, 20 (2), 2013, pp.152-168.

[10] K. Poldrugovac, M. Tekavcic, S. Jankovic, "Efficiency in the hotel industry: an empirical examination of the most influential factors," Economic research-Ekonomska istraživanja, 29 (1), 2016, pp.583-597.

[11] A. J. Singh, R. S. Schmidgall, "Analysis of financial ratios commonly used by US lodging financial executives," Journal of Retail \& Leisure Property, 2 (3), 2002, pp.201-213.

[12] P. K. CHATHOTH, "The impact of information technology on hotel operations, service management and transaction costs: A conceptual framework for full-service hotel firms." International Journal of Hospitality Management, 26, 2007, 395-408. 
[13] S. MELIñN-GONZñLEZ, \& J. BULCHAND-GIDUMAL, "A model that connects information technology and hotel performance. "Tourism Management, 53, 2016, 30-37.

[14] S. SUN \& W.-M., LU. "Evaluating the performance of the Taiwanese hotel industry using a weight slacks-based measure."Asia-Pacific Journal of Operational Research, 22, 2005, 487-512.

[15] G. SANTORO, "Evaluating performance in the hotel industry: An empirical analysis of Piedmont." Journal of Investment and Management, 4, 2015, 17-22.

[16] S. N. Hwang, T. Y. Chang, "Using data envelopment analysis to measure hotel managerial efficiency change in Taiwan," Tourism management, 24 (4), 2003, pp.357-369.

[17] K. W. Wöber, "Benchmarking for tourism organizations. An eGuide for Tourism Managers," National Laboratory for Tourism and eCommerse. University of Illinois at Urbana-Champaign. Osoitteessa http://fama2. us. es, 2011, 8080 .
[18] C. Yang, W. M. Lu, "Performance benchmarking for Taiwan's international tourist hotels," INFOR: Information Systems and Operational Research, 44.3: 2006, pp.229-245.

[19] C. F. Chen, "Applying the Stochastic Frontier Approach to Measure Hotel Managerial Efficiency in Taiwan," Tourism Management, 28, 2007, pp. 696-702.

[20] S. Setyaningsih, "Using cluster analysis study to examine the successful performance entrepreneur in Indonesia," Procedia Economics and Finance, 4, 2012, pp.286-298.

[21] O. Yim, K. T. Ramdeen, "Hierarchical cluster analysis: comparison of three linkage measures and application to psychological data," The quantitative methods for psychology, 11 (1), 2015, pp.8-21.

[22] J. J. Shuai, W. W. Wu, (2011). "Evaluating the influence of E-marketing on hotel performance by DEA and grey entropy," Expert Systems with Applications, 38 (7), 2011, pp.8763-8769. 